\title{
Editorial
}

\section{Monográfico Migraciones internacionales: Procesos de incorporación en Iberoamérica ${ }^{1}$}

Felipe, Aliaga Sáez²

Universidad de Santo Tomás, Colombia

(iD) https://orcid.org/0000-0003-4635-1132
Nicolás, Gissi Barbieri ${ }^{3}$

Universidad de Chile, Chile

(iD) https://orcid.org/0000-0001-5059-7691

\section{Beatriz, Padilla ${ }^{4}$}

Universidad de South Florida, EUA

(iD https://orcid.org/0000-0002-2359-3369

doi https://doi.org/10.29105/pgc6.11-1

Esta obra está bajo una licencia de Creative Commons Reconocimiento-NoComercial-SinObraDerivada 4.0 Internacional

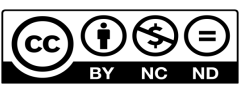

Como referenciar la editorial:

Aliaga, F., Gissi, N. \& Padilla, B. (2020). Monográfico Migraciones internacionales: Procesos de incorporación en Iberoamérica. Revista Política, Globalidad y Ciudadania, 12-18. Recuperado de http://revpoliticas.uanl.mx/index.php/RPGyC/article/view/141

En Desde la última década del siglo XX y hasta el presente, se ha constatado un incremento considerable en los flujos migratorios globales e intrarregionales (OIM 2015; PNUD 2009). En el mundo habría más de 270 millones de migrantes internacionales (Naciones Unidas, 2019), aumentando su relevancia política, económica y cultural. No sólo han crecido las corrientes migratorias en cuanto a su tamaño y diversidad, sino que se han convertido en el centro de los debates sobre políticas públicas, derechos humanos e inclusión social. Asimismo, la xenofobia, el racismo y la discriminación han acompañado y ensombrecido estos procesos. América Latina no ha estado exenta de estas tendencias y preocupaciones (vivienda, empleo, salud, educación, entre otras), aumentando los desplazamientos dentro de la región de manera importante durante los últimos años (Martínez y Orrego, 2016), siendo Argentina, Brasil, Colombia y Chile los

\footnotetext{
$1 \quad$ Escrito derivado de la Red Iberoamericana de Investigación en Imaginarios y Representaciones (RIIR), avalada por la Universidad Santo Tomás de Colombia y la Red Internacional de Estudios Migratorios, U-NÓMADES de la Universidad de Chile.

2 Doctor en Sociología y Procesos Políticos Contemporáneos por la Universidad de Santiago de Compostela. Docente investigador a tiempo completo en la Facultad de Sociología de la Universidad Santo Tomás, Colombia.

3 Doctor en Antropología por la Universidad Autónoma de México. Académico Departamento de Antropología, Universidad de Chile.

4 Doctora en Sociología, Profesora del Departamento de Sociología de la Universidad de South Florida, EUA e Investigadora del ISCTE-IUL, Portugal.
}

Revista Política, Globalidad y Ciudadanía, Vol. 6 No. 11, Enero - Junio 2020, Universidad Autónoma de Nuevo León, Monterrey, México, ISSN 2395-8448. http://revpoliticas.uanl.mx/index.php/RPGyC/article/view/141 
países que concentran actualmente el mayor flujo inmigratorio a nivel regional. Por otro lado, desde la década de 1990, España juega un papel importante como país de llegada de latinoamericanos, lo mismo que Portugal para el caso de los brasileños (Padilla, 2009).

Esta nueva realidad socio-espacial, dinámica y compleja, plantea múltiples desafíos, lecturas y valorizaciones en torno a la convivencia pluricultural y el desarrollo social en las ciudades receptoras, convocando el interés de las ciencias sociales en Iberoamérica, lo que se ha traducido en un mayor número de proyectos de investigación, cursos de especialización, centros de estudios y colaboración nacional e internacional interregional y transatlántica que reflexionan sobre las migraciones, la convivencia y la incorporación social. Estos cambios han llevado que antiguos países de emigración se conviertan en destinos migratorios (España y Portugal; México), y a la inversa, que viejos destinos de inmigración (Venezuela) se hayan tornado expulsores de inmigrantes (Gissi, Ghio y Silva, 2019), o que alberguen tanto emigración como inmigración, realidad que se hizo patente en la Península Ibérica durante la última crisis mundial (Padilla y Ortiz 2012) o en el nuevo contexto migratorio en América Latina (Perú, Colombia, Ecuador, Brasil), en la actualidad muy marcada por el éxodo venezolano. Inclusivamente, se ha hecho evidentes como los procesos políticos y electorales influencian cada vez más la inmigración (França y Padilla, 2018), por ejemplo, en los últimos dos años, el crecimiento de la migración brasileña hacia Portugal se agilizó, alcanzando un aumento de 43\% del 2018 para 2019.

Los flujos migratorios Sur-Norte y Sur-Sur, y aun los Norte-Sur, se deben tanto a factores externos como internos de los países, siendo relevantes los procesos de atracción y expulsión, así como los de globalización (Padilla, 2009). Las últimas crisis económicas internacionales y regímenes políticos neopopulistas (i.e.Venezuela) y neoconservadores (i.e. Colombia), tienen como trasfondo los procesos globalizadores de las últimas cuatro décadas, en particular la reforma estructural neoliberal que consolidó el sistema-mundo y el capitalismo global en un contexto histórico poscolonial y de división internacional y sexual del trabajo (Wallerstein, 2007; Canales, 2015). Estos fenómenos macro, productos de un modelo de desarrollo orientado a las exportaciones, han generado un nuevo "metabolismo" social que desestabiliza el espacio y la reproducción cultural, generando una "marea que levanta todos los botes" (Portes y Roberts, 2005, p. 25), debilitando los contratos sociales y mecanismos de protección, que ya eran frágiles en muchos países, y aumentando las asimetrías entre los países y regiones, y las desigualda- 
des al interior de cada sociedad, tendiendo a crecer los riesgos, la exclusión social y la pobreza (Beck y Beck-Gernsheim, 2012), así como alentando la imaginación y deseo de los individuos y sus familias (Appadurai, 2001).

Esta inestabilidad política y económica en Iberoamérica ha desembocado en una nueva actitud frente a los beneficios y riesgos de la movilidad (Douglas y Wildavsky, 1983), estableciéndose grandes movimientos hacia países de destino donde el Estado brinde mayor seguridad (Solimano, 2008), ocasionándose también cambios en la legislación migratoria de los países históricamente receptores a nivel mundial, como Estados Unidos, proclives a un mayor control migratorio (Sassen 2015; Portes 2012), especialmente con las nuevas migraciones de refugiados y los mayores controles fronterizos implementados por el presidente Trump en EE.UU.

Por otro lado, los procesos y legislaciones migratorias de los países de la península Ibérica, han variado en los últimos 30 años, a veces tornándose más amigables y otras menos, en relación a la evolución de los flujos migratorios, siendo el 2006 un año clave dada la implementación de la Agencia Europea para la Gestión de la Cooperación Operativa de las Fronteras Exteriores de los Estados Miembros de la Unión Europea (FRONTEX), la cual centró sus esfuerzos en el control de fronteras y la lucha contra la inmigración irregular, interceptando a los migrantes especialmente procedentes de África, lo cual llevó a que se bautizara al continente como la "Europa Fortaleza".

Los casos de España y Portugal, países que históricamente han sido de emigración, pasan a recibir población inmigrante a partir de los '90, pero con la crisis de 2008, experimentan nuevamente procesos de emigración. En España en tiempos del Partido Popular en el poder, se vino restringiendo la apertura migratoria, donde incluso la ultra-derecha ha ganado terreno, con partidos anti-inmigración; cuestión que va configurando una base de significados negativos en torno a las migraciones en la cual aparece el imaginario del inmigrante (Aliaga, 2008) como un “chivo expiatorio" (Aliaga, 2014), cargando las culpas de los problemas de la sociedad.

Como consecuencia de ello, en términos de recepción migrantes, se han generado nuevos ejes de producción de localidad y subjetividad, a través de nuevos objetos, formas políticas y comportamientos sociales, que han provocado un cambio en las trayectorias y destinos migratorios, así como en los procesos de incorporación y exclusión social, cuestión que se ve reflejada en el conjunto de Iberoamérica. 
Al respecto, en este monográfico contamos con nueve capítulos que ilustran estas nuevas realidades en el espacio Iberoamericano. En el texto de Yulianela Pérez García, "Estado y migración: el reflejo de las políticas en la movilidad externa de cubanos", se da cuenta sobre cómo la migración externa cubana se enfrenta a los retos de un gradual dinamismo, la diversificación de sus corrientes, la complejización de sus motivaciones y la profundización de los vínculos entre los migrantes y su país de origen, siendo la actividad normativa del Estado cubano fundamental en estas transformaciones, intentando controlar el potencial migratorio y neutralizar su impacto socioeconómico, incidiendo, entre otros elementos, en la diversificación de las expresiones de la migración y modificado los flujos, una vez que se adecuan a las oportunidades que les ofrece el marco político normativo nacional.

El capítulo de Wooldy Edson Louidor, "Trazos y trazas de la migración haitiana post-terremoto", describe los trazos de los trayectos de migrantes haitianos a lo largo del continente americano tras el terremoto del 12 de enero de 2010, así como las trazas de los impactos desastrosos de políticas migratorias hostiles de países de tránsito y destino sobre dichos migrantes, particularmente en las fronteras. A partir de la reconstrucción de las dos categorías, trazos y trazas, retomadas de Édouard Glissant y Severo Sarduy respectivamente, y de la lectura hermenéutica de un corpus de textos publicados de 2010 a 2019 sobre la migración haitiana post-terremoto, el artículo evidencia la heterogeneidad de ésta desde una doble perspectiva, geográfica y político-jurídica.

El texto de Jenny Moreno, "Políticas públicas de integración de inmigrantes. Éxitos y fracasos en Venezuela", realiza un esbozo de las políticas de atención al inmigrante en Venezuela desde 1989 hasta la actualidad, a través del análisis documental de textos científicos y de artículos de prensa. En este trabajo se describe la política de los inmigrantes desde 1989 hasta el 2003; hace referencia al periodo del presidente Hugo Chávez que marca una diferenciación con el resto de los periodos presidenciales; analiza las políticas sociales denominadas misiones que nacen en el 2003 y que se mantienen hasta el día de hoy, donde se destaca la misión identidad, destinada a dotar de documentación legal a los migrantes que llegan a Venezuela, realiza hace una revisión detallada del marco legal y finalmente describe la situación actual.

El capítulo de Donna Catalina Cabrera Serrano y Stéphanie López Villamil, "Políticas de inserción laboral de los migrantes colombianos retornados entre 2012 y 2018”, analiza la coor- 
dinación entre las políticas migratorias y las medidas en materia laboral para la población retornada en Colombia desde la aprobación de la Ley de Retorno de 2012. Considera el contexto de la emigración y del retorno en Colombia, incluyendo la participación de la población retornada en los puestos de trabajo de los países de acogida, así como las dinámicas recientes del mercado de trabajo en el país entendiendo algunos factores estructurales como el desempleo y la informalidad y la necesidad de considerar estos aspectos en el diseño de propuesta de integración socioeconómica para los retornados. Se enumeran las principales intervenciones propuestas en temas de empleabilidad y emprendimiento y se realiza un análisis detallado de los informes de gestión presentados por los Ministerios de Relaciones Exteriores y del Trabajo para el período de estudio para evidenciar la existencia de mecanismos de coordinación interinstitucional.

El capítulo de Leonardo Cavalcanti, Lorena Pereda, Marília de Macêdo y Tânia Tonhati analiza las respuestas del Estado brasileño para el caso de la migración haitiana en Brasil. La formulación de la Ley de Migración (13.445/2017) permite la entrada regulada de inmigrantes haitianos en territorio nacional, sin embargo, a través del estudio cualitativo realizado en la investigación Inmigración y crisis económica. Migración de retorno de Haití y tácticas de circularidad", en Brasilia y Curitiba durante 2018-2019, se vio que las estructuras y mecanismos de integración no se desarrollaron al mismo ritmo que las reglas de gestión del flujo, siendo un desafío para los formuladores de política migratoria en Brasil.

Por su parte, el capítulo de Juan Carlos Rodríguez Torrent y Nicolás Gissi Barbieri, "Migración haitiana en Santiago de Chile: expulsiones, imaginarios e inserción social en un Estado-nación neoliberal", sostiene que la migración haitiana cuestiona antropológicamente la idea de los límites espaciales, temporales e identitarios chilenos, ofreciendo diversos planos desde la perspectiva del migrante haitiano sobre la posibilidad de superar las barreras que enfrentan en una sociedad neoliberal. En este texto, a través de trabajo de campo y entrevistas en profundidad, se analiza la migración haitiana en Chile, comprendiendo desde sus subjetividades las vulnerables relaciones que establecen con los distintos actores con que interactúan en la vida cotidiana y el papel que juegan en la paulatina transformación de espacios sociales y laborales.

El texto de Beatriz Padilla y Thais França, "Tres décadas después... evolución de las políticas de incorporación de inmigrantes en Portugal: una nueva lectura”, discute la evolución de las políticas portuguesas de incorporación de inmigrantes, desde la década de 1980 hasta la legisla- 
ción actual de 2018. Se argumenta que, si bien se han registrado avances, no existe por parte del Estado portugués una estrategia sólida, continua y coherente. Específicamente, se abordan dos tipos de políticas de incorporación para argumentar que mientras se registraron grandes avances en las políticas de acceso a la nacionalidad, el progreso en la legislación antidiscriminación ha sido menos acentuado, pudiéndose interpretar como una expresión de racismo institucional anclado en antiguos imaginarios coloniales.

Por su parte, el capítulo de Antonia Olmos Alcaraz, "Análisis de algunos vectores sobre las migraciones internacionales en España: las políticas de integración e integración educativa a debate", analiza la gestión migratoria española, sobre la que se está edificando la actual sociedad multicultural en el país, entendiendo los procesos de integración como dinámicas de carácter unidireccional que operan en distintas esferas de la realidad (espacios educativos, laborales, etc.) y que van desde la sociedad mayoritaria al resto de la sociedad. Se realiza un análisis de carácter multinivel (comunitario, estatal y regional-local) y sectorial (destacando la incorporación educativa).

Finalmente, el ensayo de Felipe Aliaga Sáez, “Aproximación teórica a la integración de los inmigrantes en tres niveles: comprensión, adaptación e inclusión”, analiza desde una perspectiva sociológica la integración de los inmigrantes en tres niveles: a través del surgimiento de un esquema comprensivo de los individuos; adaptación a los artefactos y procesos; y la inclusión en los sistemas funcionales básicos de la sociedad. El ensayo busca plantear una tesis nueva sobre la integración, por medio de análisis y articulación conceptual desde diversos autores (P. Bourdieu, A. Giddens, A. Schütz, M. Walzer, Ch. Taylor, entre otros).

\section{REFERENCIAS}

Aliaga, F. (2008). Algunos aspectos de los imaginarios sociales en torno al inmigrante. APOSTA, Revista de Ciencias Sociales, (39), 1-40.

Aliaga, F. (2014). "El inmigrante como chivo expiatorio", en Álvarez, F., Chavero, P., y Oller, M. (Cords.). Amawta. Seminarios de investigación. Quito, Ecuador: Editorial IAEN.

Canales, A. (2015). E pur si muove. Elementos para una teoría de las migraciones en el capitalismo global. México: Universidad de Guadalajara y Porrúa.

Douglas, M. \& Wildavsky, A. (1983). Risk and culture. An essay on the selection of technical and environmental dangers. Berkeley: University of California Press 
França, T. \& Padilla, B. (2019). Imigração brasileira para Portugal: entre o surgimento e a construção midiática de uma nova vaga. Cadernos de Estudos Sociais, 33(2), 1-30.

Gissi, N., G. Ghio y C. Silva. (2019). "Diáspora, integración social y arraigo de migrantes en Santiago de Chile: Imaginarios de futuro en la comunidad venezolana", en Migraciones. Revista del Instituto Universitario de Estudios sobre Migraciones, 47, Universidad Pontificia Comillas, España. 61-88. https://revistas.comillas.edu/index.php/revistamigraciones/ article/view/9223/11246

Martínez, J. y Orrego, C. (2016). Nuevas tendencias y dinámicas migratorias en América Latina y el Caribe. OIM y CEPAL-Serie Población y Desarrollo $N^{\circ} 114$. Disponible en: http:// repositorio.cepal.org/bitstream/handle/11362/39994/1/S1600176_es.pdf (Recuperado el 9 de diciembre de 2019).

Naciones Unidas (2019). Stock migrante internacional. Disponible en: https://www.un.org/en/ development/desa/population/migration/data/estimates2/estimates19.asp (Recuperado el 08 de diciembre o de 2019).

Organización Internacional para las Migraciones (OIM). (2015). Los migrantes y las ciudades: Nuevas colaboraciones para gestionar la movilidad. Disponible en: http://publications.iom. int/system/files/wmr2015_sp.pdf (Recuperado el 17 de diciembre de 2019).

Padilla, B. \& Ortiz, A. (2012). Fluxos migratórios em Portugal: do boom migratório à desaceleração no contexto de crise. Balanços e desafios. REMHU, Rev. Interdiscip. Mobil. Hum. (39), 159-184.

Padilla, B. (2009), “As migrações latino-americanas para a Europa: uma análise retrospectiva para entender a mobilidade actual”, en Padilla, B. \& Xavier, M. (org.), Revista Migrações - Número Temático Migrações entre Portugal e América Latina, (5), 19-35.

Portes, A. (2012). Sociología económica de las migraciones internacionales. Barcelona: Anthropos.

Portes, A. y Roberts, B. (2005). "La urbanización en América Latina durante los años del experimento neoliberal", en A. Portes, B. Roberts y A. Grimson (editores). Ciudades latinoamericanas. Un análisis comparativo en el umbral del nuevo siglo. Buenos Aires: Prometeo.

Programa de las Naciones Unidas para el Desarrollo (PNUD). (2009). "Reporte de Desarrollo Humano-2009". Superando Barreras: Movilidad y desarrollo humano. Disponible en: http:// hdr.undp.org/sites/default/files/hdr_2009_es_complete.pdf(Recuperado el 08 de diciembre o de 2019).

Sassen, S. (2015). Expulsiones. Brutalidad y complejidad en la economía global. Buenos Aires: Katz.

Solimano, A. (2008). Migraciones internacionales en América Latina. Booms, crisis y desarrollo. México: FCE.

Wallerstein, I. (2007). Geopolítica y geocultura. Ensayos sobre el moderno sistema mundial. Barcelona: Kairós.

Revista Política, Globalidad y Ciudadanía, Vol. 6 No. 11, Enero - Junio 2020, Universidad Autónoma de Nuevo León, Monterrey, México, ISSN 2395-8448. http://revpoliticas.uanl.mx/index.php/RPGyC/article/view/141 